\title{
A Study on Altruism and Subjective Well-Being among Emerging Adults
}

\author{
Jeya Bala $\mathrm{P}^{1 *}$, Maria Sneha $\mathrm{S}^{2}$, Prizila $\mathrm{S}^{3}$, Priya Dharshini $\mathrm{S}^{4}$, \\ A. Antony Rose Rashmi ${ }^{5}$, J. Irin Jeya Sheela ${ }^{6}$
}

\section{ABSTRACT}

Being altruistic is one of the basic human traits but not exhibited by all, it has the capacity to transform the life of the people. The study aimed to explore whether being altruistic and perceived subjective well-being of emerging adults are related and also to find whether gender difference exist in the research variables. The participants consisted of 200 male and female undergraduate College students. Data were analysed using Karl Pearson's correlation. Results of the study indicated that there exists a significant relationship between altruism and Subjective Well-being. The study also revealed that the emerging adult did not differ based on gender on Subjective Well-being. Also, they differ based on gender on altruism.

\section{Keywords: Altruism, Subjective Well-Being, Emerging Adults}

\begin{abstract}
A rnett's conceptualization regarding a new life stage, emerging adulthood a new period of life extending for 18-25 years of age. Individuals in this stage, termed as emerging adults, are characterized by their strong desire to explore different options, it is the time of high hopes and big dreams accompanied by their optimistic outlook towards the future. The term emerging describes the exploratory, unstable and fluid quality of this inbetween period. It is also a time of anxiety as emerging adults are unsettled in life and are uncertain of where their exploration will lead.
\end{abstract}

Experiencing of this stage is although more prominent in developing countries; India, one of the developing countries has also come to take on the characteristics exhibited in this period this is evident in the increasing preference of people in their twenties to marry late, co-habit, hop jobs and try out different things until they settle-in for what works for them (Arnett, 2015). Since this phase of life comes with its own set of demands and problems, emerging adults tend to experience a lot of issues regarding their mental health or well-being in other

\footnotetext{
${ }^{1}$ Department of Psychology, St. Mary's College (Autonomous), Thoothukudi, Tamilnadu, India

${ }^{2}$ Department of Psychology, St. Mary's College (Autonomous), Thoothukudi, Tamilnadu, India ${ }^{3}$ Department of Psychology, St. Mary's College (Autonomous), Thoothukudi, Tamilnadu, India ${ }^{4}$ Department of Psychology, St. Mary's College (Autonomous), Thoothukudi, Tamilnadu, India

${ }^{5}$ Department of Psychology, St. Mary's College (Autonomous), Thoothukudi, Tamilnadu, India

${ }^{6}$ Department of Psychology, St. Mary's College (Autonomous), Thoothukudi, Tamilnadu, India *Corresponding Author
}

Received: July 07, 2021; Revision Received: September 01, 2021; Accepted: September 11, 2021

(C) 2021, Jeya Bala P, Maria Sneha S, Prizila S, Priya Dharshini S, A. Antony Rose Rashmi, J. Irin Jeya Sheela; licensee IJIP. This is an Open Access Research distributed under the terms of the Creative Commons Attribution License (www.creativecommons.org/licenses/by/2.0), which permits unrestricted use, distribution, and reproduction in any Medium, provided the original work is properly cited. 
words and the struggles of this stage put into test their positive traits like being altruistic and grateful.

\section{Subjective Well-being}

In this age of technology, people tackle new challenges that interfere with their well-being. Well-being can be defined as the experience of health, happiness and prosperity. It includes having good mental health, high life satisfaction, a sense of meaning or purpose and ability to manage to stress. A person with good well-being exhibits happiness and contentment in life.

To develop overall well-being, each type of well-being must be taken care of. Well-being is the central concept in positive psychology. Well-being can be measured and reported only by the person himself. Diener (2000), defined Subjective Well-being as a person's cognitive and affective evaluations of his or her life. These evaluations include emotional reactions to events and cognitive judgments of happiness and contentment. Thus, Subjective Well-being involves experiencing a high level of pleasant emotions, low level of negative moods and high life satisfaction (Diener et al., 2000).

In 2000, Diener proposed that the Subjective Well-being can be created as a national index. Thus, Subjective Well-being can be tracked over time. Since Diener's proposal, many researchers were interested in the field of Subjective Well-being and many researches and books were published in a minimum amount of time. Hence leading to the development of Subjective Well-being as science. The most significant reason for the increase in interest in the field of Subjective Well-being is the development of scientific methods for studying Subjective Well-being. This poised Subjective Well-being as a major scholar and applied discipline.

\section{Altruism}

The term altruism was coined by Auguste Comte in 1851 by combining the Latin word "alter" means "to other" and its Italian adjective "altru". Altruism means benevolence or living for others (Smith et al, 2006). The terms altruism and prosocial behaviour are used interchangeably. A person is said to exhibit prosocial behaviour when one's helpful action benefits others which does not necessarily serve any benefit to the self and the prosocial act may even involve risk. The, true or pure altruism is an individual's unselfish concern for the welfare of others. Altruism is a group phenomenon. It requires at least a group of two, an altruist that pays a cost and a recipient that receives a benefit.

Various religions display evidence of emphasizing the importance of helping others which explains the increased tendency of religious people to be helpful. Buddhism claims the need for altruism in sayings like "the more we care for the happiness of others, the greater our own sense of well-being becomes" (Dalai Lama, 2009). The following excerpt from The Bible "you should love your neighbour as yourself" suggests empathic-altruism. Islam describes the concept of "ithaar" which means altruism- as preferring others to oneself. The Bhagavad Gita states the virtue of "nishkaama karma" referring to actions without any expectation or desire for personal gain which encompasses altruism. Although religion portrays altruism as a salient virtue, there is a possibility of an effect of in-group bias over a religious persons' helping behaviour. 


\section{THEORIES OF ALTRUISM}

\section{Kin Selection Theory}

The kin selection theory (Simmons et al., 1977) was based on egotism- a doctrine that individual self-interest is the actual motive of all conscious action; argues that human beings tend to favour helping one's kin because of genetic similarity. Asper this theory, altruism is viewed as a behaviour that costs the individual who is on the helping end. Like kin selection is the group selection theory which can be defined as differential elimination of preformed groups of individual organisms, or of groups that have formed themselves by action of the individuals concerned (Darlington, 1977), because of pre-programmed genetic patterns of behaviour, an individual strives to fight for and facilitate safety of other members of the same group in community level or species level (Goodnight \& Stevens, 1997; Zimmer et al, 2013; Cartwright, 2000).

\section{Learning theory}

Learning theory proposes that just like any behaviour, altruism is learnt through early life experiences. This begins when a child is motivated to share food and toys with fellow schoolmates and siblings. In this way, family and society implant and reinforce altruism in young minds. According to cognitive learning theory, altruistic behaviour is learned through modelling elders, media and even from the tales they are exposed to. When children observe that helping others is recognised and appreciated by others, it serves as a motive to be altruistic.

\section{Psychodynamic theory}

Engaging in altruistic behaviour is viewed as a mature defence mechanism as it facilitates better coping with stressful events or loss. Implications of such prosocial tendency are associated with Erikson's stages of development. For instance, in pre-school stage, the child experiences Oedipus complex and role experiments where altruism helps to gain appreciation from parents and teachers and for the development of leadership skills.

\section{Social constructionist theory}

An individual gains knowledge from family, education, media, etc., which forms one's stored reality or existing reality which later develops into subjective reality- reality based on an individual's understanding and experiences. In social situations, people share ideas with one another leading to the formation of shared reality through which there exists a reciprocal influence on others resulting in a possible alteration in stored reality. For instance, a base of altruistic behaviour is passed down to an individual from one generation to the other by its members.

It is evident that there is a wide range of theories interpreting altruism. It is noteworthy that helping others is a default inclination of the human species which is based on both personality factors and social factors. Some people are just born with a greater tendency to be altruistic and such tendency is due to the contribution of genetic factors.

Martela and Ryan (2016) intended to study whether prosocial behaviour enhances subjective well-being among 79 university students. They were made to play a simple computer game for 20 minutes. Out of these $64 \%$ were women and average age of participants was 20.4 years. The final sample size was 76 , out of which 34 were in the benevolent condition. Participants were informed that for every correct answer the game donates rice to the UNWF. Whereas in controlled condition the participants were not aware of the fact. The result indicated that those in benevolent condition would experience more vitality, 
meaningfulness and enjoyment in the game than people in the controlled condition. Thus, the study indicated that benevolent game play was less draining for the players compared to control condition.

Feng and Guo (2017) studied the beneficial effect of altruism on well-being among Chinese college students. In study 1 (self-report altruism) of 525 students (136 males, 386 females, 13 unreported) mean age of 20.13 years. In study 2 (peer-rated altruism) participants were 189 college students (48 males, 138 females, 3 unreported) mean age of 19.21 years. Study on sample 1 showed that high self-reported altruism and self-reported decision to help were related to high levels of self-esteem and general well-being and low levels of anxiety, depression, and general health. Self-esteem was related to high levels of general well-being and low levels of anxiety, depression, and general health. Results of study 2 showed that peer-rated altruism positive relationship with self-esteem. Overall, altruistic behaviour can enhance self-esteem and well-being, especially for college students of low family socioeconomic status.

\section{Need for the Study}

The study concurs the argument of Seligman and Csikszentmihalyi (2000), shows that there is a negative bias dominating the field of psychology, most research studies focus on the negative aspects of human behaviour than on the positive side. Similarly, youngsters are viewed negatively by the society as troublesome and carefree beings. This study brings into focus the positive aspects of emerging adults by highlighting their sense of altruism and Subjective Well-being. After reviewing the literature, the study aimed to further the understanding of the relationship between the variables Subjective Well-being and altruism of emerging adults in Thoothukudi district.

\section{METHODOLOGY}

The study aims to understand the relationship between altruism and Subjective Well-being among emerging adults and to find if there exists a gender difference in the aspects of altruism and Subjective Well-being among emerging adults.

\section{Hypothesis}

- There will be no significant relationship between gratitude and Subjective Wellbeing among emerging adults.

- There will be no significant difference between male and female emerging adults in altruism and Subjective Well-being among.

\section{Population, sample size and Technique}

The population of this study is comprised of students of Arts and Science Colleges located in the district of Thoothukudi. Purposive sampling method was used for drawing samples from a population of emerging adults of age range 18 to 25 (mean $=18.96, \mathrm{SD}=0.85$ ). Participants consisted of 200 males $(n=96)$ and female $(n=104)$ emerging adults pursuing their Under Graduate degree.

\section{Operational definition and tool description \\ Subjective Well-Being}

Well-being can be defined and measured objectively (e.g., sufficient resources to meet basic needs, opportunities for education, lack of environmental pollutants) or subjectively; the study focuses on the subjective side. Subjective Well-Being is defined as 'people's evaluations of their life or of its various domains, e.g., health, work, family, income' or 
'people's actual feelings, both positive feelings such as happiness, pleasure or negative feelings such as pain, worry and anger' (Diener 1984; Diener et al. 1999).

This research study uses The PERMA Profiler to measure the Subjective Well-Being of the participants.

\section{The PERMA Profiler}

The PERMA Profiler was developed by Butler \& Kern (2016) to measure Subjective Well Being across multiple psychosocial domains. The tool consists of 16 items measuring five dimensions of Subjective Well Being as proposed by Seligman in his model of flourishing (2011) namely; (P)ositive emotions, the tendency toward feeling contentment and joy ( $\alpha=$ .90); (E)ngagement, being absorbed, interested and involved in an activity or the world itself $(\alpha=.58)$; (R)elationships, feeling loved, supported and valued by others $(\alpha=.86) ;(M)$ eaning, a sense of purpose and direction in life $(\alpha=.91)$; (A)ccomplishment, working toward and reaching goals $(\alpha=.79)$ and a happiness item. The items are rated on an 11-point Likert scale ranging from labels "never $=0$ " to "always $=10$ " or "not at all $=0$ " to "completely $=10$ ". The subscales are scored by finding out mean for the three items that measure each of the dimensions of PERMA. Overall well-being is the average of the 16 items. The PERMAProfiler demonstrates acceptable model fit, internal and cross-time consistency, and evidence for content, convergent, and divergent validity (Sun, Kaufman, \& Smillie; Butler \& Kern, 2016).

\section{Altruism}

Altruism refers to any organism's behaviour to promote the welfare of others by their own cost even by risking their own life. It is considered as a selfless behaviour without expecting any benefits in return. Smith et al (2006) considered altruistic behaviour as "behaviour that is intended to benefit others beyond simple sociability or duties associated with role (i.e., family or work). All altruistic behaviours, by definition, must be legal".

Helping Attitude Scale (HAS) was used to measure the altruistic behaviour of the participants.

\section{Helping Attitude Scale (HAS)}

Nickell developed the Helping Attitude Scale (HAS) to measure beliefs, feelings and behaviours associated with helping, the Helping Attitude Scale (HAS) (1998). The 20 items are rated in a 5-point Likert scale ranging from 1 (strongly agree) to 5 (strongly disagree). Items 1, 5, 8, 11, 18, 19 are reverse scored. The scores for each item are summed up to form an overall score, ranging from 20 to 100 . Per the author, a 60 is a neutral score. The scale demonstrates good internal reliability $(\alpha=.86)$ and construct validity.

The data with the questionnaires was analysed statistically using Karl Pearson's correlation coefficient and t-test with SPSS Software.

\section{RESULTS AND DISCUSSION}

\section{Table 1: Correlation coefficient showing the relationship between variables}

\begin{tabular}{ll}
\hline Variable $(\mathbf{N}=\mathbf{2 0 0})$ & $\mathbf{r}$ \\
\hline $\begin{array}{l}\text { Subjective Well-being } \\
\text { Altruism }\end{array}$ & $.266^{* *}$
\end{tabular}

Altruism

$* * p<0.01$ 
The correlation analysis results also revealed that there exists a positive significant relationship between subjective well-being and altruism among emerging adults with the $r$ value of 0.266 which is significant at 0.01 levels leading to the rejection of the null hypotheses that stated that there will be no significant relationship between subjective wellbeing and altruism among emerging adults.

As the results reveal that altruism has a positive significant relationship with subjective wellbeing, thus higher the emerging adults' scores on altruism, greater their scores on subjective well-being. This could be due to the enhancement of self-esteem and the sense of meaning an individual gets by helping others. The results obtained in the study are like the findings of Khadim and Shahid (2017) which showed a positive significant relationship between psychological well-being, gratitude and altruism.

Table 2: Significance of difference between male and female emerging adults in subjective well-being, gratitude and altruism

\begin{tabular}{lllll}
\hline Variable & Gender & N & Mean & 't' \\
\hline Subjective & Male & 94 & 6.57 & \multirow{2}{*}{$1.395^{\text {ns }}$} \\
well-being & Female & 106 & 6.85 & \\
\multirow{2}{*}{ Altruism } & Male & 94 & 76.84 & $2.930^{* *}$ \\
& Female & 106 & 80.48 & \\
\hline
\end{tabular}

ns $=$ no significance. ${ }^{* *} p<0.01$

From table 2, it could be seen that there is no significant difference in subjective well-being of male and female emerging adults, $t(191.034)=1.395^{n s}$. Thus, the null hypothesis which states that there will be no significant difference between male and female emerging adults on- subjective well-being is not rejected.

The results of the independent sample t-test revealed that there is no significant gender difference in subjective well-being among emerging adults. These results are in line with the research results of Kirmani (2016) which reveal that there was no significant gender difference in subjective well-being among college students. However, few studies found contradicting results like Friedman (2005) concluded that women tend to report greater happiness than men and thus had higher levels of subjective well-being; while Fujita (1991) observed that women had poor subjective well-being because they have more negative emotions than men. Putting it all together, the disparities in these research findings could be due to the altering gender roles with time, that is, Fujita (1991) found that women had poor subjective well-being at the time when women were denied of their rights and privileges; as time has changed a comparatively egalitarian society had developed.

From the table, it is evident that the mean value of female is higher than the mean value of male emerging adults on altruism. The value of $t$ is found to be 2.930, which shows that there is a significance difference between male and female emerging adults on altruism. This implies that female emerging adults are more altruistic than male emerging adults which deliberately leads the study to reject the null hypothesis that stated that there will be no significant difference among male and female emerging adults on altruism.

The results obtained suggest that altruism is more pronounced in female than male emerging adults. This could be explained by the natural tendency of women to care for others selflessly since they intend to reduce the distress of others by lending a helping hand. The 
findings of the current study are in line with the findings of Dreber and Essen (2011); and Fehr and Glatzle-Rutzler (2013) which identified females to be more altruistic than males.

\section{Limitations}

The limitations of the present study are discussed below,

- Only emerging adults who are pursuing their under graduate degree were drawn as samples. Working emerging adults and those who pursue post graduate degree could have been included.

- Gender is the only demographic variable employed in the study. More demographical and social variables could have been used, for example, higher and lower socio-economic status, birth order or family type.

- All the tools used in the study were developed by western authors and the questionnaires could have been translated to the mother tongue of the sample for better understanding of the items. (or could have used an Indian authors' tool or some tools which are more appropriate/relevant to this society/culture)

The present study does not explain a causal relationship between the variables.

\section{Implication of the Study}

The research provides better understanding of the relationship between subjective well-being and altruism among Indian emerging adults. The findings of this research would help further in the application of positive psychology in counselling settings. Furthermore, the present study sheds light on the positive aspects of emerging adults thus invoking a shift of attitude toward youngsters from viewing them as trouble-makers to people of virtues. Results of the current study could be used to spread awareness among people who have a misconception about emerging adults. Instead of viewing them as indifferent, emerging adults can be portrayed as what they are, optimistic explorers of life.

\section{REFERENCES}

Butler, J., \& Kern, M. L. (2016). The PERMA-Profiler: A brief multidimensional measure of flourishing. International Journal of Wellbeing, 6, 1-48.

Derber, A., Von Essen, E., and Ranehill, E. (2011). Gender and competition in adolescence: task matters. Exp. Econ. 17, 154-174. DOI:10.1007/s10693-013-9361-0.

Cartwright, J. (2000). Evolution and human behaviour: Darwinian perspectives on human nature. Massachusetts: MIT press.

Diener, E. (1984). Subjective well-being. Psychological Bulletin, 95, 542-575.

Dalai Lama XIV. (2007)/ (2009). Preface in "Mind in Comfort and Ease". Boston, MA: Wisdom Publications.

Darlington, P. J. (1977). Proc. Natl. Acad. Sct. USA 74, 1647-1651.

Darlington, P. J. (2017). Altruism: Its characteristics and evolution, proc. Natl. Acad. Sci, 75(1), 385-389.

Diener, E., Lucas, R, E., and Oishi, S. (2000) Subjective well-being: the science of Happiness and life satisfaction 63-64.

Diener, E., Suh, E. M., Lucas, R. E., \& Smith, H.L. (1999). Subjective well-being: three decades of progress. Psychological Bulletin, 125, 276-302.

Egilmer, E., Naylar, J., (2017). Altruism \& popularity. International journal of educational Methodology, 3(2), 65-74, http://www.ijem.com.

Fehr, E., Glatzle-Rutzler, D., and Sutter, M. (2013) The development of egalitarianism, altruism, spite and parochialism in childhood and adolescence. Eur. Econ. Rev. 64, 369-383. DOI: 10.1016/j.euroecorev.2013.09.006. 
Feng, L., \& Guo, Q. (2017). Beneficial effect of altruism on well-being among Chinese college students: the role of self-esteem and family socioeconomic status. Journal of Social Service Research, 43(3), 416-431. doi: org/10.1080/01488376.2016.1242449

Friedman, P., (2005). The relative contribution of forgiveness, Gratitude, prayer and spiritual transcendence in reducing distress and enhancing well-being, Quality of life and happiness, Paper presentation at the $3^{\text {rd }}$ annual mid-year research conference on religion and spirituality.

Fujita, F., (1991). Gender differences in negative effect and well-being: The case for emotional intensity, Journal of personality and social psychology, 61, 427-434.

Goodnight, C. J., \& Stevens, L. (1997). Experimental studies of group selection: What do they tell us about group selection in nature. American Naturalist, 150, 59-79.

Khadim, U., Shahid, A., (2017). Gratitude \& Altruism as predictors of psychosocial wellbeing among adolescents.

Kirmani, M. N. (2015). Gratitude, forgiveness and subjective well-being among college going students. International Journal of Public Mental Health and Neurosciences, 2(2), 1- 10 .

Maner, J. K., \&Gailliot, M. T. (2006). Altruism and egoism: Prosocial motivations for helping depend on relationship context. European journal of social psychology. doi:10.1002/ejsp.364

Martela, F., \& Ryan, M. R. (2016). Prosocial behaviour increases well-being and vitality even without contact with the beneficiary. causal \& behaviour evidence, 40: 351357.

Nickell GS. The Helping Attitude Scale. Paper presented at $106^{\text {th }}$ Annual Convention of the American Psychological Association at San Francisco. 1998.

Seligman, M. (2011). Flourish: A visionary new understanding of Happiness and Wellbeing, 12-24, 28.

Seligman, M. E. P. (2011). Flourish: A visionary new understanding of happiness and wellbeing. New York: NY: Free Press.

Seligman, M. E., \& Csikszentmihalyi, M. (2000). Positive psychology: An introduction (Vol. 55, No. 1, p. 5). American Psychological Association.

Simmons, R. G., Klein, S. D., \& Simmons, R. L. (1977). Gift of Life: The Social and Psychological Impact of Organ Transplantation. Wiley, London, UK.

Smith, S, W., Smith, S, L., Pieper, K, M., et al. (2006). Altruism on American television: Examining the amount of and context surrounding acts of helping and sharing. Journal of communication, $56,707-727$.

Zimmer, C., \& Emlen, D. J. (2013). Evolution: Making sense of life (1st ed.). Greenwood village. co: Roberts and company publishers.

\section{Acknowledgement}

The author(s) appreciates all those who participated in the study and helped to facilitate the research process.

\section{Conflict of Interest}

The author(s) declared no conflict of interest.

How to cite this article: Jeya Bala P, Maria Sneha S, Prizila S, Priya Dharshini S, A. Antony Rose Rashmi, J. Irin Jeya Sheela (2021). A Study on Altruism and Subjective Well-Being Among Emerging Adults. International Journal of Indian Psychology, 9(3), 1354-1361. DIP:18.01.126.20210903, DOI:10.25215/0903.126 